\title{
Convolvulaceae no Parque Nacional de Sete Cidades, Estado do Piauí, Brasil
}

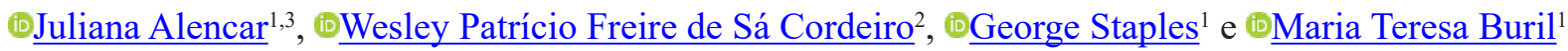

Recebido: 22 novembro 2018; aceito: 22 agosto 2019

Como citar: Alencar, J., Cordeiro, W.P.F.S., Staples, G. \& Buril, M.T. 2019. Convolvulaceae no Parque Nacional de Sete Cidades, Estado do Piauí, Brasil. Hoehnea 46: e992018. http://dx.doi.org/10.1590/2236-8906-99/2018.

ABSTRACT - (Convolvulaceae Juss. in the Sete Cidades National Park, Piauí State, Brazil). Convolvulaceae, including 58 genera and approximately 1880 species, have a cosmopolitan distribution with greater diversity in the tropical regions. In Brazil, 24 genera and 403 species are found in all phytogeographic domains. The Sete Cidades National Park is located in the northeastern region, Piauí State, at an ecotone between Cerrado and Caatinga. Despite the abundance of Convolvulaceae in these environments and the biodiversity potential of Piauí State, there are no floristic studies about this family published for the State. This project aimed to inventory Convolvulaceae in the PARNA Sete Cidades. For this purpose, we visited the Herbarium Graziela Barroso (TEPB) collection and also made a field expedition. The species collected were identified based on the specialized bibliography and the voucher material was deposited in the Herbarium Professor Vasconcelos Sobrinho (PEUFR). Representatives of five genera were found: Cuscuta, Daustinia, Evolvulus, Ipomoea and Jacquemontia, totaling eight species.

Keywords: biodiversity, conservation unit, ecotone, taxonomy, vines

RESUMO - (Convolvulaceae Juss. no Parque Nacional de Sete Cidades, Estado do Piauí, Brasil). Convolvulaceae possui distribuição cosmopolita, incluindo 58 gêneros e cerca de 1.880 espécies, com maior diversidade na região tropical. No Brasil, são reconhecidas 403 espécies distribuídas em 24 gêneros, encontradas em todos os domínios fitogeográficos. O Parque Nacional de Sete Cidades está localizado na região Nordeste, Estado do Piauí, e apresenta fisionomia predominante de transição entre Cerrado e Caatinga. Apesar da representatividade de Convolvulaceae nesses ambientes e do potencial de biodiversidade do Estado do Piauí, não existe estudo de flora da família para o Estado. A presente pesquisa teve como objetivo inventariar Convolvulaceae no PARNA Sete Cidades. Para isto, foi realizada visita ao acervo do Herbário Graziela Barroso (TEPB) e expedições de coleta. As espécies foram identificadas baseadas na bibliografia especializada e o material coletado foi depositado no Herbário Professor Vasconcelos Sobrinho (PEUFR). Foram encontradas oito espécies em cinco gêneros: (Cuscuta, Daustinia, Evolvulus, Ipomoea e Jacquemontia).

Palavras-chave: biodiversidade, ecótono, taxonomia, trepadeiras, Unidade de Conservação

\section{Introdução}

Convolvulaceae Juss. pertence ao clado das Lamiídeas na ordem Solanales (APG IV 2016). A família é caracterizada por apresentar geralmente trepadeiras com folhas alternas, sem gavinhas, cálice dialissépalo, corola campanulada a infundibuliforme, com áreas mesopétalas conspícuas, estames epipétalos, ovário súpero e, na maioria das espécies, fruto capsular e presença de látex (Staples \& Brummit 2007). São cosmopolitas, porém mais diversas nos Trópicos, e circunscrevem cerca de 1880 espécies em 58 gêneros (Convolvulaceae Unlimited 2018). No Brasil, atualmente são reconhecidos 24 gêneros, sendo dois endêmicos, e aproximadamente 400 espécies, das quais 182 são endêmicas (Flora do Brasil 2020 em constr.).

São mais frequentes em áreas de vegetação aberta e afloramentos rochosos, por vezes dunas ou regiões pantanosas (Staples \& Brummit 2007), ocorrem em

1. Universidade Federal Rural de Pernambuco, Departamento de Biologia, Área de Botânica, Programa de Pós-Graduação em Botânica, Laboratório de Sistemática de Angiospermas, Rua Dom Manoel de Medeiros, s/n, Dois Irmãos, 52171-900 Recife, PE, Brasil

2. Universidade Federal Rural de Pernambuco, Departamento de Biologia, Área de Botânica, Programa de Pós-Graduação em Botânica, Laboratório de Taxonomia Vegetal, Rua Dom Manoel de Medeiros, s/n, Dois Irmãos, 52171-900 Recife, PE, Brasil

3. Autor para correspondência: alenca1@hotmail.com 
todos os domínios fitogeográficos do Brasil com maior representatividade nos biomas Cerrado, Caatinga e Mata Atlântica, respectivamente (Flora do Brasil 2020 em constr.). É uma das famílias mais diversas dos ecossistemas semiáridos do Brasil e apontada entre as dez famílias mais numerosas da Caatinga (Queiroz et al. 2006).

Alguns estudos em outras áreas da região Nordeste trazem resultados interessantes como, por exemplo, o da microrregião do Cariri Paraibano no qual a diversidade de Convolvulaceae foi marcada pela ocorrência de 24 espécies de seis gêneros diferentes (Buril et al. 2013); na microrregião do Alto Capibaribe, em Pernambuco, foram registradas 20 espécies distribuídas em cinco gêneros (Nepomuceno et al. 2016); e, a família foi considerada como uma das mais ricas em número de espécies na comunidade savânica no município de Rio de Fogo, Estado do Rio Grande do Norte (Oliveira et al. 2012).

Apesar da representatividade da família nestes domínios e do potencial de biodiversidade do Estado do Piauí (Santos-Filho \& Soares 2011), cuja predominância territorial encontra-se na Caatinga, não existem estudos direcionados à flora de Convolvulaceae para o Estado. Deste modo, o presente estudo teve como objetivo realizar o tratamento taxonômico das espécies de Convolvulaceae ocorrentes no PARNA Sete Cidades, fornecer subsídios para sua identificação e contribuir para o conhecimento e conservação da flora local.

\section{Material e métodos}

O Parque Nacional de Sete Cidades (PNSC) foi criado pelo Decreto Federal $n^{0} 50.744$, de 8 de junho de 1961 (IBDF 1979), priorizando a conservação da biodiversidade dos biomas Cerrado e Caatinga ali encontrada (Cavalcante 2013). O parque é dividido por "cidades", sendo sete conhecidas e mapeadas para o público visitante; e no seu interior são encontrados diversos sítios com pinturas rupestres. Está localizado no Estado do Piauí nos municípios de Piracuruca e Brasileira $\left(04^{\circ} 05^{\prime}\right.$ a $04^{\circ} 15^{\prime} \mathrm{S}$ e $41^{\circ} 30^{\prime}$ a $\left.41^{\circ} 45^{\prime} \mathrm{W}\right)$, compreendendo uma área de 6.221,48 ha, delimitada em um perímetro $36,2 \mathrm{~km}$ (figura 1). O PNSC se encontra numa região de transição entre os domínios fitogeográficos da Caatinga e do Cerrado (figura 2); tendo uma dominância do bioma Cerrado na composição da vegetação (IBDF 1979).

Foram realizadas caminhadas por diferentes ambientes do PNSC, alcançando uma boa cobertura de

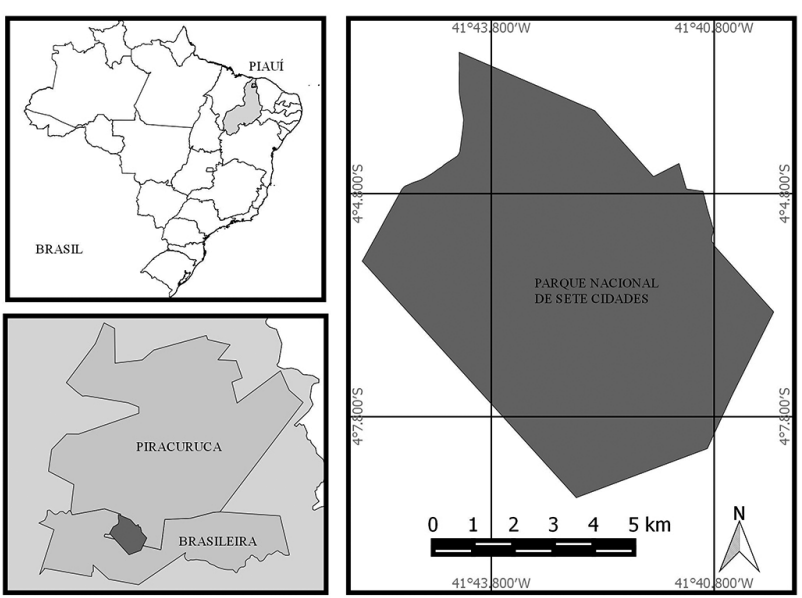

Figura 1. Mapa do Brasil com destaque para a localização do PNSC, localização da área do parque dentro dos municípios do Estado do Piauí e perímetro do Parque Nacional de Sete Cidades.

Figure 1. Location map of the Sete Cidades National Park in the State of Piauí, location of the park area indside of the municipalities of the Piauí State and perimeter of the Sete Cidades National Park.

sua área territorial. A amostragem e herborização do material foram procedidas conforme Mori et al. (1989). Cinco ramos férteis de cada espécie foram coletados, flores e frutos foram fixados em álcool $70 \%$ para as análises morfológicas em laboratório. As populações em campo foram fotografadas, as coordenadas geográficas e informações sobre o habitat foram registradas em caderneta de campo. O material coletado foi depositado no Herbário Professor Vasconcelos Sobrinho (PEUFR) e as duplicatas serão doadas aos herbários K, TEPB e RB.

Foram analisados os espécimes de Convolvulaceae depositados na coleção do Herbário Graziela Barroso (TEPB). A identificação dos táxons foi feita a partir de bibliografia especializada (Yuncker 1922, Yuncker 1923, Ooststroom 1934, Austin \& Cavalcante 1982, Simão-Bianchini 1998, Buril \& Alves 2011, Buril 2013; Buril et al. 2014, Buril et al. 2015). As descrições seguiram as terminologias de Hickey (1973), Harris \& Harris (2001) e Simpson (2006).

\section{Resultados}

Convolvulaceae é representada no PNSC por oito espécies em cinco gêneros: Cuscuta L. (uma sp.), Daustinia Buril \& A.R. Simões (uma sp.), Evolvulus L. (duas spp.), Jacquemontia Choisy (duas spp.) e Ipomoea L. (duas spp.). Os gêneros encontrados na área de estudo podem ser diferenciados pelo tamanho e cor de suas corolas, morfologia das sépalas, do estigma e tipo de tricomas. As espécies foram encontradas, principalmente, nas áreas de vegetação aberta do 

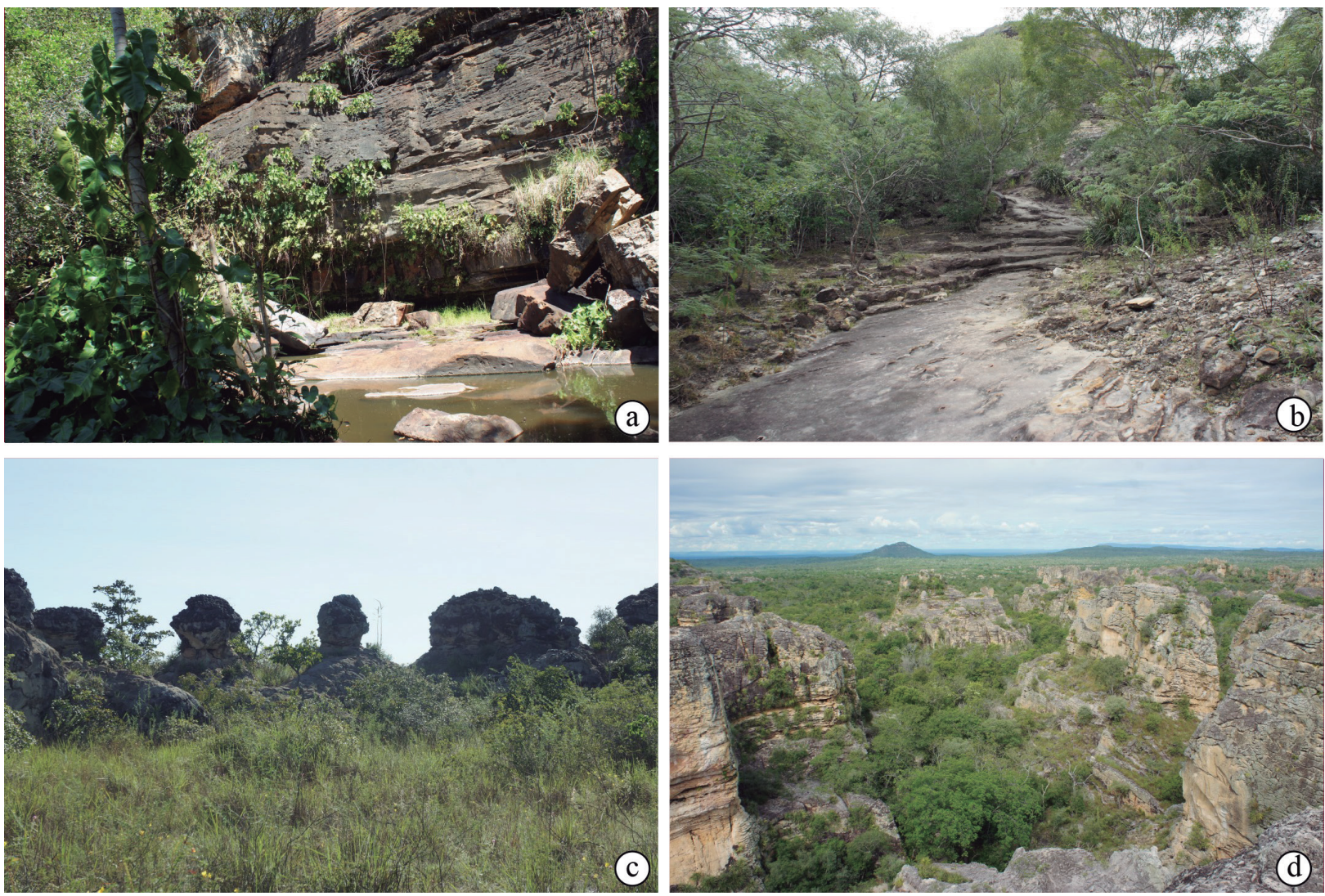

Figura 2. Fisionomias da vegetação do Parque Nacional de Sete Cidades, Estado do Piauí, Brasil. a. Cachoeira do Riachão, durante período seco. b. estrato arbustivo- arbóreo. c. estrato herbáceo-arbustivo. d. afloramentos rochosos.

Figure 2. Physiognomies of the vegetation of the Sete Cidades National Park, Piauí State, Brazil. a. Cachoeira do Riachão, during dry period. b. Shrub-arboreal stratum. c. Herbaceous-shrub stratum. d. Outcrops.

parque, como as bordas de estradas. Apesar da região semiárida ser um ambiente propício à ocorrência de Convolvulaceae, a diversidade encontrada dentro do parque foi menor do que esperávamos, considerando outros trabalhos que demonstram um incremento de pelo menos $50 \%$ na diversidade quando são realizadas monografias focadas na família em detrimento de inventários florísticos anteriores (Oliveira et al. 2012, Buril et al. 2013, Nepomuceno et al. 2016). Apesar disso, esta é a primeira contribuição para o conhecimento de
Convolvulaceae no Estado do Piauí, além de ser uma contribuição para os avanços no conhecimento da flora desta região que foi historicamente subamostrada e negligenciada por taxonomistas. Chama a atenção principalmente a baixa diversidade do gênero Ipomoea, aqui representado por apenas duas espécies, e que sempre desponta em todos os levantamentos como o grupo mais rico entre as Convolvulaceae. Vale destacar, entretanto, que apesar da baixa diversidade, I. hewittacea forma uma imensa população na área.

Chave de identificação para as espécies de Convolvulaceae ocorrentes no Parque Nacional de Sete Cidades Estado do Piauí

1. Plantas aclorofiladas, parasitas

1. Cuscuta partita

1. Plantas clorofiladas, não-parasitas

2. Folhas ensiformes, sésseis; inflorescência terminal

3. Cimeira espiciforme; corola hipocrateriforme, serícea com tricomas apenas nas áreas mesopétalas

4. Evolvulus pterocaulon

3. Cimeira corimbiforme; corola rotada, externamente serícea 3. Evolvulus ericifolius

2. Folhas lanceoladas, elípticas, oboelípticas, oblongas, ovais, ovadas, reniformes ou cordiformes, pecioladas; inflorescência axilar

4. Tricomas ramificados, 3-6-armados; sementes glabras 
5. Erva volúvel; sépalas externas ovadas a lanceoladas, base truncada; corola totalmente branca a azul-clara 7. Jacquemontia chrysanthera

5. Erva ereta; sépalas externas deltoides, base cordada; corola branca com fauce vinácea 8. Jacquemontia gracillima

4. Tricomas simples ou ausentes, sementes com indumento

6. Folhas com margem denteada, venação craspedódroma, corola amarela, estames homodínamos .....

2. Daustinia montana

6. Folhas com margens inteiras ou 3-lobadas, venação broquidódroma, corola rósea ou branca, estames heterodínamos

7. Erva reptante; tirso 3-5-floros; sépalas oblongas, glabras; ovário cônico 5. Ipomoea asarifolia

7. Erva volúvel; tirso 3-floros; sépalas lanceoladas, hirsutas; ovário cilíndrico 6. Ipomoea hewittacea

1. Cuscuta partita Choisy, Mém. Soc. Phys. Genève 9: 284 , t. 5 , f. 3.1841 [publ. 1842].

Figura 3a

Erva volúvel, áfila, coloração laranja, glabra. Cimeira, 4-5 mm compr., 3-40 flora, cálice ca. $1 \mathrm{~mm}$ compr., lobos triangulares ou lanceolados, ápice agudo, margem inteira. Corola branca, urceolada, 2-2,5 $\times 2-2,5 \mathrm{~mm}$, glabra, lobos triangulares com ápice reflexo. Estames menores que os lobos da corola, homodínamos; filetes ca. 0,5 mm compr., glabros; anteras amarelas, ca. 0,5 compr., ovais. Escamas menores ou do mesmo tamanho do tubo da corola. Ovário globoso, ca. $1 \times 1 \mathrm{~mm}$; estiletes ca. $1 \mathrm{~mm}$ compr., desiguais; estigmas 2, exsertos, globosos. Fruto cápsula aberta por circuncisão, envolta pela corola seca. Semente não observada.

Material examinado: BRASIL. Piauí: Piracuruca, Parque Nacional de Sete Cidades, em campo limpo úmido, 9-VII-2009, M.R.A. Mendes et al. 548 (TEPB, n.v., UB!). Material adicional: BRASIL. PIAUÍ: Piracuruca, Rodovia Confiança, 11-VI-2016, J.A.A.M. Lourenço et al. 110 (PEUFR).

Não é possível identificar espécimes de Cuscuta pela macromorfologia e tão pouco por fotografias: identificações taxonômicas precisas neste gênero dependem de dissecções cuidadosas das escamas infrastaminais, usando flores preservadas em meio líquido ou reidratadas a partir de um voucher de herbário. Essas escamas infrastaminais fornecem caracteres críticos para identificações precisas. No PARNA não encontramos indivíduos de Cuscuta, porém foi coletado material no entorno do parque (J.A.A.M Lourenço et al. 110); também foram analisados os espécimes depositados no TEPB e a duplicata de Mendes et al. 548 (UB!, emprestado ao PEUFR). A identificação morfológica do gênero é bastante complexa, os principais caracteres para distinguir C. partita das demais espécies é o tamanho das escamas infrastaminais, cápsula aberta por circuncissão e o ápice do lobo da corola reflexo. Os indivíduos encontrados no entorno do Parque foram coletados sobre vegetação rasteira, em solo arenoso.

2. Daustinia montana (Moric.) Buril \& A. R. Simões, Phytotaxa 197(1): 60. 2015

Figuras 3b, 4 h-i

Erva volúvel, entrenós 0,8-6,1 cm compr., velutinos, tricomas simples. Pecíolo 0,4-2,3 cm compr., velutino, tricomas simples; folhas simples, cartáceas, 1,2-6,0 × 0,7-3,5 cm, lanceoladas, ovadas, base truncada, arredondada, ligeiramente cordada, ápice mucronado a mucronulado, margem denteada, coloração verde in vivo, discolores quando secas; serícea a tomentosa, tricomas simples; venação craspedódroma. Cimeira capituliforme, axilar, 2,3-7,4 cm compr., 4-11 flora; brácteas $0,8-1,7 \times 0,2-0,9 \mathrm{~cm}$, ovais a lanceoladas, pubescentes, tricomas simples. Sépalas desiguais, base truncada, ápice agudo, margem denticulada; as externas ca. $7 \times 2 \mathrm{~mm}$, ovais a elípticas, base truncada, ápice agudo, margem denticulada; as internas, 5,4-7,3 × 1,1-1,4 mm, ovais a oblongas; velutinas, tricomas simples. Corola amarela, infundibuliforme, ca. $11 \times 23 \mathrm{~mm}$, glabra. Estames insertos, homodínamos; filetes ca. 2,5 mm compr., pubescentes na base; anteras amarelas ou brancas, ca. $1 \mathrm{~mm}$ compr., elípticas. Ovário globoso, ca. $1 \times 1 \mathrm{~mm}$.; estilete ca. 5,4 mm compr.; estigma inserto, lobos-2, globosos; disco nectarífero, 5-lobado. Cápsula ca. $6 \times 4 \mathrm{~mm}$, sementes esféricas, ca. $3 \mathrm{~mm}$ diâm., marrons, pubescentes, tricomas simples, dourados a marrons.

Material examinado: BRASIL. PIAUÍ: Piracuruca, Parque Nacional de Sete Cidades, 7-VI-2016, J.A.A.M. Lourenço et al. 79 (PEUFR); 7-VI-2016, J.A.A.M. Lourenço et al. 84 (PEUFR); 8-VI-2016, J.A.A.M. Lourenço et al. 89 (PEUFR); 8-VI-2016, J.A.A.M. 

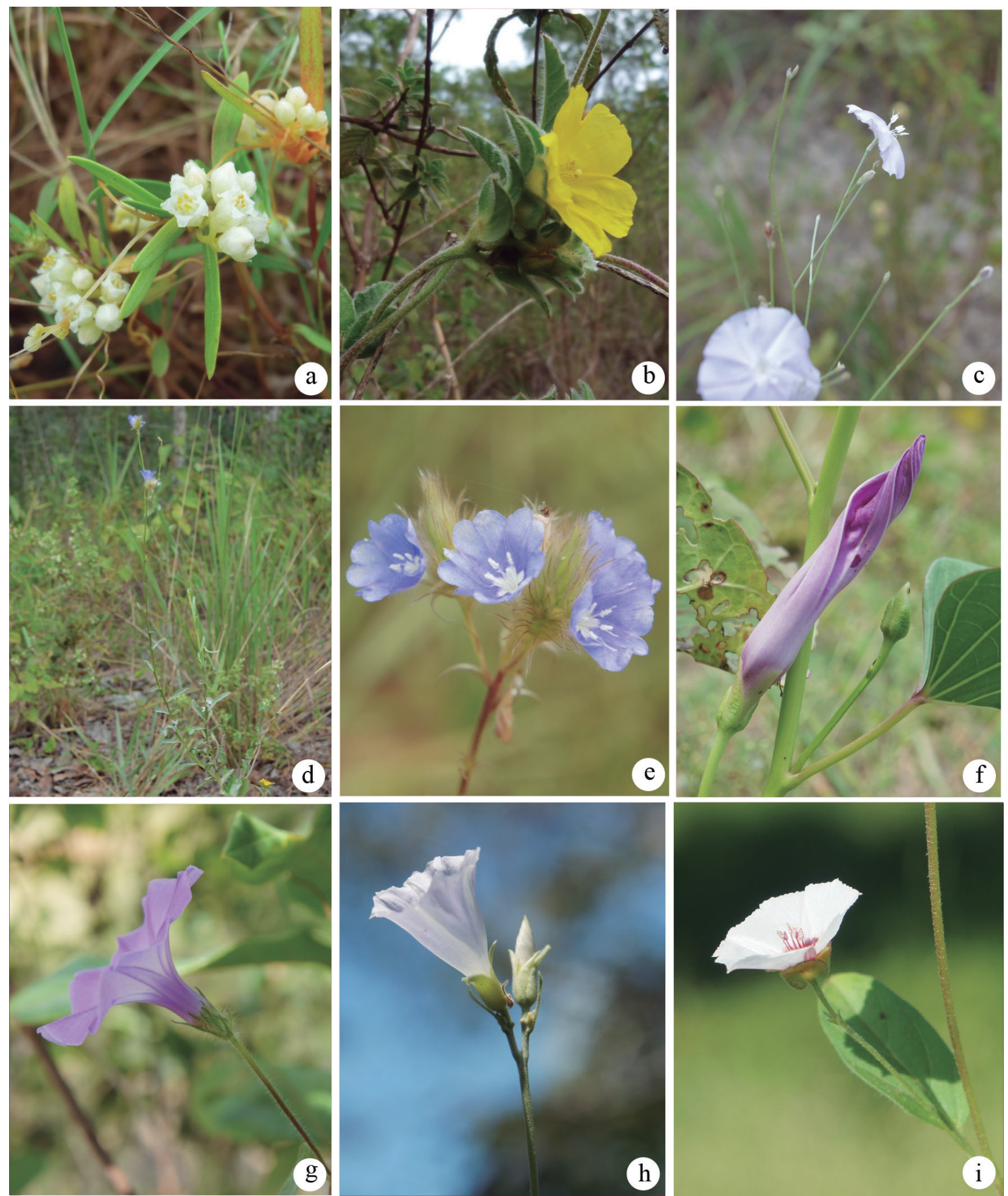

Figura 3. Diversidade morfológica de Convolvulaceae no Parque Nacional de Sete Cidades, Piracuruca, Estado do Piauí, Brasil. a. Cuscuta partita (material complementar, Lourenço et al. 110), inflorescência. b. Daustinia montana, inflorescência. c. Evolvulus ericifolius, inflorescência. d-e. Evolvulus pterocaulon, hábito e inflorescência. f. Ipomoea asarifolia, flor. g. Ipomoea hewittacea, flor. h. Jacquemontia chrysanthera, inflorescência. i. Jacquemontia gracillima, inflorescência.

Figure 3. Morphological diversity of Convolvulaceae at the Sete Cidades National Park, Piracuruca, Piauí State, Brazil - a. Cuscuta partita (complementary material, Lourenço et al. 110), inflorescence. b. Daustinia montana, inflorescence. c. Evolvulus ericifolius, inflorescence. d-e. Evolvulus pterocaulon, habit e inflorescence. f. Ipomoea asarifolia, flower. g. Ipomoea hewittacea, flower. h. Jacquemontia chrysanthera, inflorescence. i. Jacquemontia gracillima, inflorescence. 
Lourenço et al. 90 (PEUFR); 6-VII-2007, M.R.A. Mendes et al. 53 (TEPB); 25-VII-2009, M.R.A. Mendes et al. 464 (TEPB); 22-V-2005, R. Barros et al. 2334 (TEPB); Brasileira, Parque Nacional de Sete Cidades, 9-IV-2002, A. Carvalho \& C.G. Lopes 113 (TEPB).

Daustinia montana pode ser encontrada desde o Estado do Piauí até o do Rio de Janeiro, em áreas de Caatinga, Cerrado, campo rupestre e Mata Atlântica (Buril et al. 2014). Na área de estudo é facilmente reconhecida por ser a única espécie da família com folhas com margens denteadas e corola amarela. A espécie é frequente na área, e pode ser encontrada na beira das estradas do parque e áreas abertas com vegetação arbustiva e solo arenoso.

3. Evolvulus ericifolius Mart. ex Schrank, Pl. Rar. Hort. Monac. 2: t. 94. 1821.

Figuras $3 \mathrm{c}, 4 \mathrm{c}$

Erva ereta, ca. $30 \mathrm{~cm}$ alt., entrenós 0,4-1,7 cm compr., seríceos, tricomas simples. Folhas sésseis, simples, cartáceas, $0,3-0,6 \times 0,05-0,1 \mathrm{~cm}$, ensiformes, base atenuada, ápice mucronado, margem inteira, coloração discolor; seríceas, tricomas simples; venação hifódroma. Cimeira corimbiforme, terminal, 1-3-flora, ca. $5 \mathrm{~cm}$ compr.; pedicelo 1-2,5 cm compr., bractéolas ensiformes, ca, $1 \times 1 \mathrm{~mm}$, base equilateral, ápice cuspidado, margem inteira, seríceas. Sépalas desiguais; as externas 2-2,5 ×1 mm, elípticas, base truncada, ápice obtuso ou mucronulado, margem escariosa; as internas 2-2,5 × 1,8-2,5 mm, largoelípticas a orbiculares, base truncada, ápice obtuso ou mucronulado, margem escariosa; seríceas, tricomas simples. Corola azul, rotada, ca. $8 \mathrm{~mm}$ compr., seríceas externamente. Estames exsertos, homodínamos; filetes ca. 1,8 mm compr., anteras brancas, ca. $1 \mathrm{~mm}$ compr., sagitadas. Ovário globoso ca. 0,8 × 0,7 mm; estilete ca. $5 \mathrm{~mm}$ compr., bífido, estigmas exsertos, bífidos, filiformes; disco nectarífero sinuoso. Fruto não observado.

Material examinado: BRASIL. PiAuí: Piracuruca, Parque Nacional de Sete Cidades, 7-VI-2016, J.A.A.M. Lourenço et al. 77 (PEUFR); 7-VI-2016, J.A.A.M. Lourenço et al. 80 (PEUFR); 8-VI-2016, J.A.A.M. Lourenço et al. 86 (PEUFR); 25-VI-1999, R.Barros et al. 244 (TEPB); 15-XI-2001, A. Carvalho et al. 55 (TEPB); 14-X-2007, M.R.A. Mendes et al. 457 (TEPB); 30-IX-2007, M.R.A. Mendes et al. 369 (TEPB); 8-VII-2009, M.R.A. Mendes et al. 514 (TEPB); 7-VII-2007, M.R.A. Mendes et al. 69
(TEPB); 6-VII-2007, M.R.A. Mendes et al. 55 (TEPB); 13-X-2007, M.R.A. Mendes et al. 409 (TEPB); 12-X-2007, M.R.A. Mendes et al. 380 (TEPB); 13-X-2007, M.R.A. Mendes et al. 435 (TEPB); 12-V-2007, M.R.A. Mendes \& J.L.Viana 08 (TEPB).

Evolvulus ericifolius tem populações com poucos indivíduos, sendo encontradas nas bordas das trilhas do PNSC em solo arenoso. Diferencia-se de E. pterocaulon, a outra espécie do gênero ocorrente na área, principalmente pelas inflorescências corimbiformes (vs. espificiformes). Alguns espécimes no TEPB foram identificados como E. gypsophiloides, uma espécie que é muito semelhante a $E$. ericifolius. De acordo com a chave para as espécies da seção Linoidei na monografia de Ooststroom para o gênero (1934), essas espécies podem ser distintas pelas sépalas, da seguinte forma: E. ericifolius tem sépalas externas elípticas, de 2-2,5 $\mathrm{mm}$ de comprimento, obtusas ou mucronadas, as sépalas internas amplamente elípticas a orbiculares com margens escariosas; enquanto que E. gypsophiloides possui sépalas com 5-7 mm de comprimento, oblongo-lanceoladas e acuminadas. $\mathrm{O}$ indumento das folhas mencionado na chave não parece ser um caráter confiável para discriminar as espécies, porém, o tamanho e a forma das sépalas são carateres mais distintivos na delimitação das espécies de Convolvulaceae. Além disso, a distribuição no Brasil dada por Ooststroom (1934) sugere que estas espécies são alopátricas: E. ericifolius é relatado nos Estados da Bahia, Goiás e Rio de Janeiro, enquanto E. gypsophiloides é relatado no Ceará, Pernambuco, Bahia e Mato Grosso. Entretanto, a Flora do Brasil (2020 em constr.) tem relato mais atualizado de sua distribuição em Estados do Norte, Nordeste, Centrooeste e Sudeste brasileiros.

4. Evolvulus pterocaulon Moric., P1. Nouv. Amer. 140. t. 84. 1844.

Figuras 3d-e, $4 \mathrm{~g}$

Erva ereta, ca. $40 \mathrm{~cm}$ alt., entrenós 1-1,6 cm compr., tomentosos, tricomas simples. Folhas sésseis simples, cartáceas, 1,8-3,7 × 0,3-0,9 cm compr., ensiformes, base truncada, ápice mucronado, margem inteira, tomentosas, tricomas simples; venação actinódroma basal. Cimeira espiciforme, terminal, 10-16-flora, 1,5-3,8 cm compr., brácteas ensiformes, base truncada, ápice mucronado, margem inteira; bractéolas $7 \times 1 \mathrm{~mm}$, ensiformes, base truncada, ápice mucronado, margem inteira; seríceas, tricomas simples. Sépalas desiguais; as externas, $7 \times 1 \mathrm{~mm}$, lanceoladas, 


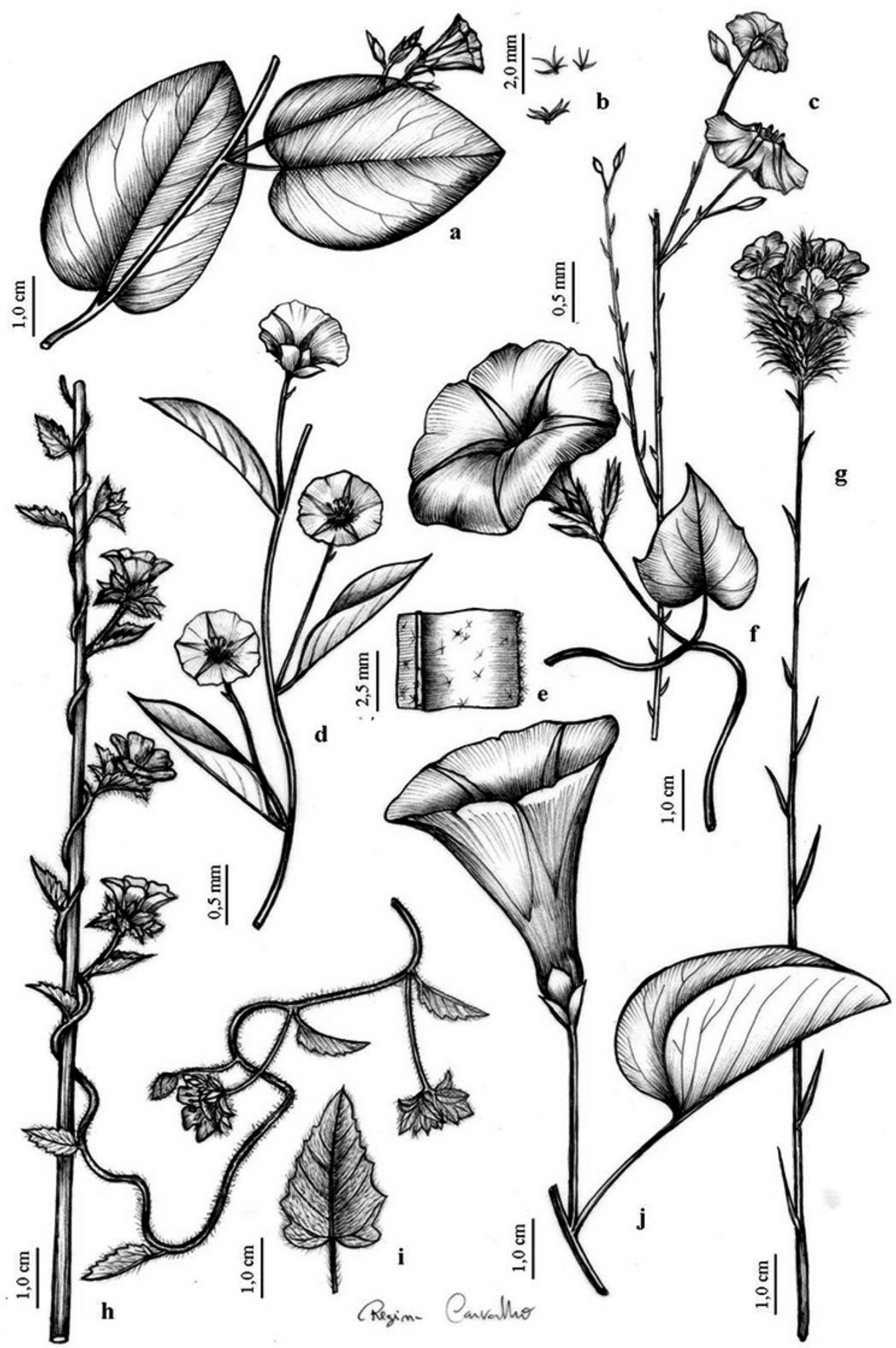

Figura 4. a-b. Jacquemontia chrysanthera. Ramos floríferos, tricomas. c. Evolvulus ericifolius. Ramo florífero. d-e. Jacquemontia gracillima. Ramo florífero, tricomas. f. Ipomoea hewittacea. Ramo florífero. g. Evolvulus pterocaulon. Ramo florífero. h-i. Daustinia montana. Ramo florífero, folha. j. Ipomoea asarifolia. Ramo florífero.

Figure 4. a-b. Jacquemontia chrysanthera. Flowering branches, trichomes. c. Evolvulus ericifolius. Flowering branch. d-e. Jacquemontia gracillima. Flowering branch, trichomes. f. Ipomoea hewittacea. Flowering branch. g. Evolvulus pterocaulon. Flowering branch. h-i. Daustinia montana. Flowering branch, leaf. j. Ipomoea asarifolia. Flowering branch. 
base oblíqua, ápice mucronado, margem não escariosa; as internas, 4,25 × $1 \mathrm{~mm}$, lanceoladas, base oblíqua, ápice mucronado, margem inteira; seríceas, tricomas simples. Corola azul, hipocrateriforme, 11-12 mm, serícea nas áreas mesopétalas, tricomas simples. Estames exsertos, homodínamos; filetes ca. 2,5 mm compr.; anteras brancas ca. $1 \mathrm{~mm}$ compr., sagitadas. Ovário globoso, ca. $0,6 \times 0,6 \mathrm{~mm}$.; estilete ca. $9 \mathrm{~mm}$ compr., estigmas exsertos, bífidos, filiformes, brancos, disco nectarífero sinuoso. Fruto não observado.

Material examinado: BRASIL. PIAUIi: Piracuruca, Parque Nacional de Sete Cidades, 7-VI-2016, J.A.A.M. Lourenço et al. 78 (PEUFR); 7-VI-2016, J.A.A.M. Lourenço et al. 83 (PEUFR); 16-XI-2001, A. Carvalho et al. 72 (TEPB); Brasileira, Parque Nacional de Sete Cidades, 25-VIII-2000, R. Barros \& A. R. França 901 (TEPB).

Evolvulus pterocaulon ocorre com relativa frequência nas bordas das estradas do parque, sendo encontrado em pequenas populações em vegetação herbáceo-arbustiva com solo areno-argiloso. A diferenciação para E. ericifolius já foi discutida sob os comentários desta espécie.

5. Ipomoea asarifolia (Desr.) Roem. \& Schult., Systema Vegetabilium, edit. 15 bis 4: 251. 1819. Figuras $3 \mathrm{f}, 4 \mathrm{j}$

Erva reptante, ca. $20-30 \mathrm{~cm}$ alt., entrenós 3-5,5 cm compr., glabra. Pecíolo 4-7 cm compr., glabro, folhas simples, cartáceas, 4-5 × 4-6 cm, inteiras, reniformes, base cordada, ápice obtuso, margem inteira, concolores, verde in vivo, marrom-esverdeado desidratada, glabras; venação broquidódroma. Tirsos axilares, 3-5-floros, 11-13 cm compr.; axila do pedicelo pubérulo; brácteas $1-1,7 \times 1-1,7 \mathrm{~mm}$, triangulares. Sépalas desiguais, as externas ca. $5,5 \times 3,5 \mathrm{~mm}$, oblongas, base truncada, ápice arredondado a emarginado, mucronado, margem inteira; as internas $13 \times 7,5 \mathrm{~mm}$, oblongas, base truncada, ápice arredondado a emarginado, mucronado, margem inteira, glabras. Corola rósea, infundibuliforme, $60-70 \mathrm{~cm}$, glabra. Estames insertos, heterodínamos; menores ca. $12 \mathrm{~mm}$ compr., maiores ca. $23 \mathrm{~mm}$ compr.; filetes menores ca. $6 \mathrm{~mm}$. compr., o maior ca. $17 \mathrm{~mm}$ compr.; anteras magentas, ca. $6 \mathrm{~mm}$ compr., oblongas. Ovário cônico, $1 \times 1 \mathrm{~mm}$; estilete 20-23 mm; estigma inserto, lobos-2, globosos; disco nectarífero discretamente 5-lobado, glabro. Fruto não observado.

Material examinado: BRASIL. PIAUÍ: Piracuruca, Parque Nacional de Sete Cidades, 8-VI-2016, J.A.A.M.
Lourenço et al. 88 (PEUFR); 11-X-2001, A. Carvalho et al. 18 (TEPB).

Apenas uma pequena população de Ipomoea asarifolia foi encontrada próximo à ponte entre a $7^{\mathrm{a}}$ cidade e o Olho d'água dos Milagres. Entretanto, essa espécie ocorre frequentemente na região, fora do parque. É facilmente reconhecida pelo crescimento reptante e folhas reniformes.

6. Ipomoea hewittacea (Kuntze) J. R. I. Wood \& Scotland, Kew Bull. 70(3)-31: 38. 2015. Figuras 3g, 4f

Erva volúvel, entrenós 10-14 cm compr., hirsuta, tricomas simples. Pecíolo 2-3 cm compr., hirsuto, folhas simples, cartáceas, 3-3,5 × 1,2-1,5 cm, lobos ovais, base cordada, ápice agudo, margem inteira a 3-lobada, concolores in vivo, discolores quando secas, face adaxial marrom, abaxial verde, tricomas simples; venação broquidódroma. Tirsos axilares, 7-11 cm compr., 3-floros, pedicelo hirsuto; brácteas ca. $1 \times 0,2 \mathrm{~cm}$, estreito-ovais, hirsutas. Botão fusiforme, glabro. Sépalas desiguais, externas ca. $14 \times 4 \mathrm{~mm}$, lanceoladas, base arredondada, ápice estreito agudo, margem inteira; internas 10-11 ×4 mm, lanceoladas, base arredondada, ápice estreito agudo, margem inteira, hirsutas. Corola rósea ou branca, infundibuliforme, $40-45 \mathrm{~mm}$ compr., pubescente nas áreas mesopétalas, tricomas simples. Estames insertos, heterodínamos; os menores ca. $12,5 \mathrm{~mm}$ compr., os maiores ca. $16 \mathrm{~mm}$ compr.; anteras oblongas, ca. 2,5 mm compr., magentas. Ovário cilíndrico, ca. $1 \times 1 \mathrm{~mm}$; estilete ca. $2 \mathrm{~cm}$ compr.; estigma inserto, lobos-2, globosos; disco nectarífero inteiro ca. $2 \mathrm{~mm}$ alt. Cápsula ca. 5,5 × 5,5 mm, globosa, glabra, sementes ovoides, ventralmente achatadas, ca. $4 \times 2,5 \mathrm{~mm}$, marrom escuras, velutinas, cinéreas.

Material examinado: BRASIL. PIAUIi: Piracuruca, Parque Nacional de Sete Cidades, 7-VI-2016, J.A.A.M. Lourenço et al. 81 (PEUFR); 7-VI-2016, J.A.A.M. Lourenço et al. 82 (PEUFR); 7-VII-2007, M.R.A. Mendes et al. 77 (TEPB).

Ipomoea hewittacea foi recentemente combinada em Ipomoea por Wood et al. (2015), o qual ainda incluiu I. piresii O'Donell sob seus sinônimos. É amplamente distribuída no PNSC apresentando grandes populações associadas a todos os estratos vegetacionais. São encontradas variações na tonalidade da corola (rosa a lilás) em uma mesma população. É facilmente diferenciada de $I$. asarifolia, pelas sépalas 
distintamente hirsutas (vs. glabras), e pelo hábito volúvel (vs. reptante).

\section{Jacquemontia chrysanthera Buril, Brittonia 63(4):} 436. 2011.

Figuras $3 \mathrm{~h}, 4 \mathrm{a}-\mathrm{b}$

Erva volúvel, entrenós ca. 2-9 cm compr., velutina, tricomas 4-6-armados. Pecíolo 0,9-2,2 cm compr., velutino, tricomas 4-6-armados. Folhas simples, cartáceas, 4,2-7,3 × 2,7-5 cm, inteiras, ovais, ovadas, oboelípticas, base subcordada, ápice mucronado, margem inteira a ondulada, discolores, mais escuras na face adaxial, velutinas, tricomas 4-6 armados; venação camptódroma. Dicásio umbeliforme, axilar, 10,4-46,4 mm, 5-16-floro; bractéolas lineares, 4,5-7,3 × 0,3-0,5 mm. Botão fusiforme, glabro. Sépalas desiguais, as externas 6,7-8,7 × 2,7-3,7 mm, ovadas a lanceoladas, base truncada a arredondada; ápice acuminado, arredondado ou agudo, margem inteira; as internas 5,4-6,12 × 2,71-3,40 mm, ovadas, base truncada, ápice acuminado, margem inteira hialina; velutinas, tricomas 4-6 armados. Corola branca a azul-clara, infundibuliforme, ca. $2 \mathrm{~cm}$ compr., glabra. Estames insertos, homodínamos; filetes ca. $2,5 \mathrm{~mm}$ compr.; anteras amarelas, ca. $2 \mathrm{~mm}$ compr., elípticas. Ovário cônico ca. $1,2 \times 1 \mathrm{~mm}$; estilete ca. $5 \mathrm{~mm}$ compr.; estigma inserto, lobos-2, dorsiventralmente achatado. Cápsula ca $5 \times 4 \mathrm{~mm}$, glabra, sementes ovoides, ca. $3,5 \times 2 \mathrm{~mm}$, glabras.

Material examinado: BRASIL. PIAUí: Piracuruca, Parque Nacional de Sete Cidades, 7-VI-2016, J.A.A.M. Lourenço et al. 85 (PEUFR); 10-VI-2016, J.A.A.M. Lourenço et al. 101 (PEUFR).

Espécie endêmica do Brasil, Jacquemontia chrysanthera teve sua ocorrência registrada para os Estados da Bahia, Ceará, Piauí, Pernambuco e Minas Gerais (Flora do Brasil 2020 em constr.). No PARNA foi encontrada uma pequena população próxima ao portão norte (saída para Piracuruca). Difere de $J$. gracillima, a outra espécie do gênero ocorrente na área, pelo seu hábito volúvel (vs. ereto) e a corola totalmente branca a azul claro (vs. corola branca com fauce vinácea), além das sépalas ovadas a lanceoladas com base truncada a arredondada( $v s$. deltoides com base cordada).

8. Jacquemontia gracillima (Choisy) Hallier f., Bot. Jahrb. Syst. 16(4-5): 541. 1893.

Figuras 3i, 4d-e
Erva ereta, ca. $30 \mathrm{~cm}$ alt., entrenós 0,8-2,7 cm compr., pubescente, tricomas 3-5 armados. Pecíolo ca. 0,2 cm compr., glabrescente, tricomas 3-5 armados, folhas simples, membranáceas, 1,4-2,3 × 0,6-1 cm, inteiras, elípticas a oblongas, base arredondada a levemente assimétrica, ápice cuneado, margem inteira, pubescente, tricomas 3-5-armado; venação camptódroma. Monocásio, axilar, 2,5-7 cm compr., 3-floros; bractéolas ca. $3 \mathrm{~mm}$ compr. Botão fusiforme, pubescente. Sépalas desiguais, as externas 4,2 ×4,9 mm compr., deltoides, base cordada, ápice acuminado, margem inteira; as internas $5 \times 2,8 \mathrm{~mm}$, obovadas, base arredondada, ápice acuminado, margem inteira, pubescentes, tricomas 3-5-armados. Corola branca com fauce vinácea, infundibuliforme, ca. $1 \mathrm{~cm}$ de compr., glabra. Estames exsertos, homodínamos; filetes ca. $3 \mathrm{~mm}$ compr.; anteras brancas, ca. $1 \mathrm{~mm}$ compr., oblongas. Ovário globoso, ca. $1 \times 1 \mathrm{~mm}$, estilete ca. 3,8 mm compr.; estigma exserto, lobos-2, cilíndricos; disco nectarífero 5-lobado. Cápsula ca. $4 \mathrm{~mm}$ diâm., glabra, sementes ovoides, ca. $3 \times 2 \mathrm{~mm}$, ventralmente achatadas, glabras.

Material examinado: BRASIL. PIAUí: Piracuruca, Parque Nacional de Sete Cidades, 8-VI-2016, J.A.A.M. Lourenço et al. 87 (PEUFR); 25-VII-2009, M.R.A. Mendes \& B.B. Annunziata 582 (TEPB).

Jacquemontia gracillima foi encontrada apenas em beira de estrada próximo a $7^{\mathrm{a}}$ cidade do PNSC, em solo areno-argiloso com pedregulhos, não sendo muito frequente na área do Parque Nacional de Sete Cidades. Endêmica do Brasil, têm distribuição geográfica relatada para a maioria dos Estados do Nordeste, Centro-oeste e Sudeste brasileiros (Flora do Brasil 2020 em constr.). Diferencia-se das demais espécies da família encontradas no Parque por ser a única a possuir a corola branca com a fauce vinácea.

\section{Agradecimentos}

Ao Conselho Nacional de Desenvolvimento Científico e Tecnológico (CNPQ) pelo projeto de pesquisa (PVE 314725/2014-8) e bolsa de pesquisa do primeiro e segundo autores. Regina Carvalho, a ilustração. À curadora e funcionários do Herbário Graziela Barroso; ao Instituto Chico Mendes de Conservação da Biodiversidade (ICMBio); ao gestor Sr. Cristino Silva e demais funcionários do Parque Nacional de Sete Cidades; a Francisco Diego Sousa Santos e Silmara Cecília Nepomuceno pelas valiosas informações acerca dos gêneros Evolvulus e Cuscuta, respectivamente. 


\section{Literatura citada}

APG (Angiosperm Phylogenetic Group) IV. 2016. An update of the angiosperm phylogenetic group classification for the orders and families of flowering plants: APG IV. Botanical Journal of the Linnean Society 181: 1-20.

Austin, D.F. \& Cavalcante, P.B. 1982. Convolvuláceas da Amazônia. Museu Paraense Emilio Goeldi, Belém.

Buril, M.T. 2013. Sistemática e filogenia de Jacquemontia Choisy (Convolvulaceae). Tese de Doutorado, Universidade Federal de Pernambuco, Pernambuco.

Buril, M.T. \& Alves. M. 2011. A new species of Jacquemontia (Convolvulaceae) from northeastern Brazil. Brittonia 63: 436-441.

Buril, M.T., Delgado Júnior, G.C., Barbosa, M.R.V. \& Alves, M. 2013. Convolvulaceae do Cariri Paraibano, PB, Brasil. Revista Nordestina de Biologia 21: 3-26.

Buril, M.T., Simões, A.R., Carine, M. \& Alves, M. 2014. Austinia, a new genus of Convolvulaceae from Brazil. Phytotaxa 186: 254-260.

Buril, M.T., Simões, A.R., Carine, M. \& Alves, M. 2015. Daustinia, a replacement name for Austinia (Convolvulaceae). Phytotaxa 197: 60.

Cavalcante, L.C.D. 2013. Parque Nacional de Sete Cidades, Piauí, Brasil: biodiversidade, arqueologia e conservação de arte rupestre. Mneme-revista de humanidades, v.14, n.32, pp. 1-22.

Convolvulaceae Unlimited. 2018. Disponível em http:// convolvulaceae.myspecies.info/ (acesso em 29-III-2018).

Flora do Brasil 2020 em construção. 2016. Jardim Botânico do Rio de Janeiro. Disponível em http:// floradobrasil.jbrj.gov.br/ (acesso em 18-XI-2016).

Harris, J.G. \& Harris, M.W. 2001. Plant identification terminology: an illustrated glossary. 2 ed: Spring Lake, Utah.

Hickey, L.J. 1973. Classification of the architecture of dicotyledonous leaves. American Journal of Botany 60: 17-33.

IBDF (Instituto Brasileiro de Desenvolvimento Florestal, Ministério da Agricultura). 1979. Plano de Manejo Parque Nacional de Sete Cidades. Brasília. Disponível em http:/www.icmbio.gov.br/portal/images/ stories/imgs-unidades-coservacao/PARNA\%20SETE\%20 CIDADES.pdf (acesso em 29-VIII-2016).
Mori, A.S., Silva, L.A.M., Lisboa, G. \& Coradin, L. 1989. Manual de Manejo do Herbário Fanerogâmico. 2 ed. Centro de Pesquisas do Cacau, Ilhéus.

Nepomuceno, S.C., Athiê-Souza, S.M. \& Buril, M.T. 2016. Convolvulaceae da Microrregião do Alto Capibaribe, Brasil. Hoehnea 43: 371-386.

Oliveira, A.C.P., Penha, A.S., Souza, R.F. \& Loiola, M.I.B. 2012. Composição florística de uma comunidade savânica no Rio Grande do Norte, Nordeste do Brasil. Acta Botanica Brasilica 26: 559-569.

Ooststroom, S.J.V. 1934. A monograph of the genus Evolvulus. Mededeelingen van het Botanisch Museum en Herbarium van de Rijks Universiteit te Utrecht 14: 1-267.

Queiroz, L.P., Conceição, A. \& Giulietti, A.M. 2006. Nordeste Semi-árido: caracterização geral e lista das fanerógamas. In: A.M. Giulietti, \& L.P. Queiroz. Diversidade e caracterização das fanerógamas do semi-árido brasileiro. Associação Plantas do Nordeste, vol. I, Recife, pp. 40-41.

Santos-Filho, F.S. \& Soares, A.F.C.L. 2011. Biodiversidade do Piauí: Pesquisas e Perspectivas. Editora CRV, Curitiba.

Simão-Bianchini R. 1998. Ipomoea L. (Convolvulaceae) no Sudeste do Brasil. Tese de Doutorado, Universidade de São Paulo, São Paulo.

Simpson, M.G. 2006. Plant Systematics. Elsevier Academic Press, Canada.

Staples, G.W. \& Brummitt, R.K. 2007. Convolvulaceae. In: V.H. Heywood, R.K. Brummitt, A. Culham \& O. Seberg (eds.). Flowering plant families of the world. Royal Botanic Gardens, Kew, pp. 108-110.

Wood, J.R.I., Carine, M.A., Harris, D., Wilkin, P., Williams, B. \& Scotland, RM. 2015. Ipomoea (Convolvulaceae) in Bolivia. Kew Bulletin 70: 1-124..

Yuncker, T.G. 1922. Revision of the South American species of Cuscuta. I. American Journal of Botany 9: 557-575.

Yuncker, T.G. 1923. Revision of the South American species of Cuscuta II. American Journal of Botany 10: 1-17. 